\title{
Challenges in Online Teaching amidst Covid Crisis: Impact on Engineering Educators of Different Levels
}

\author{
Addepalli Mallinadh Kashyap ${ }^{1}$, SripathiVijaya Sailaja ${ }^{2}$,Kandarpa Venkata Rama Srinivas ${ }^{3}$,Sivangi Suryanarayana Raju ${ }^{4 \#}$ \\ ${ }^{1}$ Assistant Professor, Department of Civil Engineering, GIET Engineering College, Rajahmundry, A.P., India \\ ${ }^{2}$ Assistant Professor, Department of EEE, GIET Engineering College, Rajahmundry, A.P., India \\ ${ }^{3}$ Professor, Department of Mathematics, GIET Engineering College, Rajahmundry, A.P., India \\ ${ }^{4}$ Former Principal, , GIET Engineering College, Rajahmundry, A.P., India \\ \# Mentor of The Project
}

\begin{abstract}
COVID-19 thrashed the field of education with a greater challenge by sudden forced closure of educational institutions and to seek for alternative approaches in present mandatory forced physical distancing. The task of efficiently tune the learners to equip with global competencies and to nurture the skill for developing services to meet the utmost requirements of the society. As the present condition is uncertain and keeping this aspect in view, as a best compensation to the existing forced loss to learners, the educational institutions in India adopted virtual mode for regular teaching and learning processes. Virtual approach is not a new mode but it was confined to special learning aspects rather than traditional mode of teaching as of now. Under these circumstances, being an immediate alternative to the existing huge loss, several challenges need to be addressed such as the immediate adoption of this online pedagogy by engineering educators of different levels. The present paper describes the results of survey conducted on teachers of different levels and different specialisations conducted in July-August 2020. In the first phase of study, the survey is conducted among senior career educators regarding the faculty and learner confidence in technology enabled learning and in the second phase of study, the extent of interaction by the educators with the learners and parents and Technological Pedagogical Knowledge (TPK) ability of educators is studied.
\end{abstract}

\section{Corresponding Author:}

Addepalli Mallinadh Kashyap

Department of Civil Engineering,

GIET Engineering College,

Rajahmundry,

A.P., India.

Email ID: mallinadhkashyap@gmail.com

The senior career educator's survey results reported that efficacy of the online teaching should not be measured during the crisis time and further suggested that the educational curriculum in India should be restructured in order to achieve success in online teaching pedagogy. The survey results of the early career educators reported that $80 \%$ of the people effectively communicated with the learners and parents on a regular basis. The rest of the people reported that due to various reasons like non-responsiveness of learners as well as parents, they were unable to maintain social contact during this period. Further, $90 \%$ of them trying their best to enhance their teaching skills by the effective utilization of online teaching aids to make it as best as conventional pedagogical process and $10 \%$ of them reported that they have not utilized online teaching aids at all.

Keywords: Education, Approaches, Virtual Mode, Online Pedagogy

\subsection{Introduction}

With the rapid impact of COVID-19 pandemic throughout the world, all most all the countries have implemented lockdown at various spans as it found to be the best to control the spread of the transmitive corona virus infectious disease. As an attention, all the educational institutions in India were abruptly closed from third week of March, yielded to considerable damage in educational sector right from primary to higher standards. In view of highest level of urgence to minimize the disturbances and for the benefit of academic community, the educational institutions adopted the online teaching as a substitute to conventional mode of teaching. At this juncture, several challenges need to be addressed such as quick adoption and accustom of online pedagogy by engineering educators of different levels.However, the level of extent to which the educators have mastered such challenges successfully and what are the various factors in that regard remain unknown.

The implementation of forced closure of educational institutions occurred and searching for alternative approaches in view of covid pandemic has been basically supported by extensive transformation in technological advancements and innovations in terms of digitalization, not least in the context of education[1-2]. Subsequently, the digitalization in many educational institutions has become a predominant issue, independently of and before the pandemic. However, in India, many educational institutions are performing relatively better with reference to the expected ICT transformation process, but it is confined for some special aspects only but not for regular teaching. Hence, there is a question whether the sudden forced closure may be a better compensation for educators and learners utilization of ICT tools. TPACK frame work is highly useful in online teaching, but the question of how best the competence and education opportunities of educators to learn digital 
competence contribute to their mastery of knowledge to face the challenges of the pandemic situation also at debate.

Apart from the points raised, this paperalso reports the survey results of challenges in online teaching amidst COVID19 crisisand impact on engineering educators of different levels and different specialisations i.e., senior level educators, moderate experienced educators and early career educators. The senior career educators are the teachers with a teaching experience of more than 25 years and the early career educators are the teachers with a teaching experience of within the 5 years and moderate educators are with the experience in between. The targeted group faculty have been working at institutes of different capacities in different places of the country. It is expected that the early career educators should be able to adapt to the digitized online teaching challenges that are imposed by the pandemic as they are better well-versed with digital technologies i.e., a part of $21^{\text {st }}$ Century learners. Having recent completion of their higher education and also must have gone through recent advancements in digitization, the early career educators are expected to be relatively more competent in the utilization of online teaching applications [3]. The survey conducted is an attempt to mostly address the furnished research questions by posing to the senior career engineering educators and early career educators:

a. The extent of faculty and learner confidence in technology enabled learning?

b. How best do early career educators able to maintain interaction with learners and parents while mastering the crucial challenges of teachinglearning process (i.e., provision of online content, introduction of new learning concepts, provision of different tasks to learners, feedback provision, conduction of online assessment and evaluation) by using online tools and TPK ability of educators?

c. The experiences of senior level educators being utilised in the augmentation of this utmost needed approach for better learning output for the learners. etc.

The relevant information gathered via an online survey from different parts of country during lateral week of July and August 2020, the span at which all the educational institutions were completely closed and teaching learning process occurred via online mode. Certain new measurement tools were developed in order to conceptualize the survey to the global pandemic. This paper provides the analysis and discussion on the digitalization role in the field of education during this pandemic. Further, in this study, an attempt also made to discuss the implications for engineering educator's competence facets and the design of sustainable learning opportunities for early career teachers who are expected to lead the engineering education profession in the future.

\subsection{Online Teaching during Forced Closure}

The COVID 19 pandemic arousal has posed certain unrivalled challenges requiring the educators to adapt the online teaching immediately. Till March 2020, the typical teaching conditions at educational institutions were categorized by the learners who convened in classrooms as per their time tables and the educators who covered their courses by using standard methodologies by means of conventional face to face interaction where the learners are required to listen to their facilitators, work individually or collaboratively and predominantly refurnish knowledge in the formative and summative assessments [4]. Further, the utilization of ICT was limited and confined to some special aspects of learning in India [5-6]. The sudden closure of educational institutions confronted the educators, learners and parents with an extremely new condition [7]. The process of continual teaching and learning is possible only with the immediate adoption of online teaching and learning pedagogy which requiring all the educators and learners to utilize different digital resources and tools to solve the raised problems by the pandemic [8]. Apart from the instructional objectives and goals, the educators were also required to maintain contact with their learners virtually so as to account for the social integration of their student Learning Groups (SLG's).

\subsection{ICT Process in Educational Institutions}

In fact, the sudden shift to full scale transformation like online teaching pedagogy was unexpected and rapid due to the arousal of pandemic reflected a considerable transformation of ICT process in Indian educational system. The digitalization of education has gained prominence years ago but in fact was confined to some special aspects of learning [5-6]. A very important argument relating to bridge the gap between learners traditional learning and development at institutions and the skills and experiences that the learners required to enter the information economy, the institution curriculum should increasingly be intervened with ICT mode and the learners should be given certain specific opportunities to utilize advanced technological resources for innovative and creative problem solving [9].

In India, where the present area of research mostly concentrated, it is of so necessity to prepare the learners for a society in which the digital literacy plays most important role and of course the same has been well acknowledged. The research report by NITI AYOG [10] regarding utilization of ICT tools in secondary schools in the year 2015 recommended that the educators required to be empowered and motivated by means of training to utilize ICT for all the necessary exercises of curriculum and such type of programs need to be organized on a continual basis. It is also of very importance to host educators discussion sessions, may happen at regular basis to share various issues and challenges along with positive results so as to establish professional communities within and among the educational institutes.Further, the educational institutions should monitor regularly and identify the ICT training needs for the 
teachers so as to arrange training programs as required. There is a greater requirement to focus and develop the learning resources as well as the teaching resources by the educators and the resources should be placed on the website in order to encourage the learning of the learners. Even though, these recommendations are for secondary schools, majority of these recommendations are being implemented in the higher educational institutions in India, but these are confined to some special learning aspects only.

Despite these recommendations, certain critical queries have emerged in relation to how the digital classrooms and technologies improve learner's learning ability and knowledge [11]. Previous studies recommends that digital resources and technologies may enable new opportunities for teaching and learning pedagogy and the ICT is increasing day by day in the educational institutions in recent times [12] However, there is a potential impact on teaching and learning, the mere existence of software technology hardware does not necessarily lead to learner's progress [13]. Despite, the advanced and technical infrastructure is necessary to impart ICT in the context of instruction, the educators and learners must also be encouraged and to be supported in the utilization of digital resources.

The research data found to be related to the concepts of pedagogy which could be utilized to apply ICT efficiently in addition to how educators can be trained to utilize technology in ways that are pedagogically sufficient. It is crucial to examine deeply the principles of teaching and learning and how educators integrate digital technology in the context of online pedagogy [14]. On par with the online teaching learning process, the query regarding how opportunities enable learning the digital competence should be imparted and implemented with the objective of fostering the early career educator competences so that they are prepared in a better way for digitalization in educational institutions remain open.

\subsection{Educator's Competence}

In the present empirical research, the educator's competencies are understood as 'Context oriented, cognitive performance disposals which are responsive functionally to the conditions and situations arise in specific domains [15]. Extensive studies related to generic models pertaining to professional competence that comprises cognitive and affective areas of motivation are available [16]. On par with cognitive domain area, depending on Shulman's model of classification of teacher knowledge (1987), the researchers now a days generally differentiate the educator's CK, PCK and GPK [17]. Educators must come on this range of professional knowledge and accustom to coherent understandings and skills in order to master the core challenges involved in teaching [18].

As a response to the increasing importance of full scale ICT transformation process of educational institutions, these educator knowledge categories have been extended to indulge the knowledge that is necessitated to command the challenges that are included with the utilization of ICT in online teaching and learning process[19]. A typical model developed by Mishra et al [20] excellently defined the teacher's TK along with CK, PCK and GPK. It is termed as TPACK frame work and it specifies different intersections of TK with CK and GPK and is often resembled by using a Venn diagram. However, for the current study, we focused only on TPK ability, as we conducted survey on educators of different levels and subject domains requiring a common perspective on teaching knowledge. So as to achieve success in online teaching process, confidence is very much required apart from content knowledge and skills. On par with the affective-motivational area, we considered educator's selfefficiency as a decisive tool for educators to adapt to online teaching learning process in the pandemic forced closures.

\subsection{Methodology}

\subsection{Data Collection}

The collection of data started in last week of July 2020 and concluded by the end of August. We targeted a set of 100 early career educators 100 moderate experienced educators and 50 senior career educators all over the country, who volunteered to participate in our survey. The average age of early career educators ranges from 25-30 years, moderate experienced educators ranges from 33-45 and the senior career educators ranges from 50-65 years of different levels and different specialisations in the field of engineering. The survey is divided into two phases. In the first phase of study, the survey conducted among targeted group of career educators regarding the faculty and learner confidence in technology enabled learningand the measuring tools used in this phase are furnished in Table 1 and in the second phase of study, the extent of interaction by the educators with the learners and parents and Technological Pedagogical Knowledge (TPK) ability of educators is studied and reported.

Table 1: Measuring tools to find the faculty confidence in Technology usage

\begin{tabular}{|l|l|c|}
\hline \multicolumn{1}{|c|}{ Measuring Tool } & \multicolumn{1}{|c|}{ Item Description } & $\begin{array}{c}\text { No. of } \\
\text { items }\end{array}$ \\
\hline $\begin{array}{l}\text { Operation \& } \\
\text { Application of } \\
\text { technology }\end{array}$ & $\begin{array}{l}\text { Organization, } \\
\text { Structuring, Securing } \\
\text { the digital data in } \\
\text { online, Managing the } \\
\text { tools over internet }\end{array}$ & 04 \\
\hline $\begin{array}{l}\text { Information \& } \\
\text { Research }\end{array}$ & $\begin{array}{l}\text { Performing target } \\
\text { data research over } \\
\text { internet and } \\
\text { databases }\end{array}$ & 02 \\
\hline $\begin{array}{l}\text { Communication } \\
\text { \& Cooperation }\end{array}$ & $\begin{array}{l}\text { Establishing proper } \\
\text { communication } \\
\text { means with students } \\
\text { and digital } \\
\text { cooperation by } \\
\text { faculty to students }\end{array}$ & 02 \\
\hline
\end{tabular}




\begin{tabular}{|l|l|c|}
\hline $\begin{array}{l}\text { Making \& } \\
\text { Presenting }\end{array}$ & $\begin{array}{l}\text { Plan, Design and } \\
\text { Execution of digital } \\
\text { resources in proper } \\
\text { way to address the } \\
\text { learners by using } \\
\text { online platforms }\end{array}$ & 03 \\
\hline $\begin{array}{l}\text { Feedback and } \\
\text { Reflections }\end{array}$ & $\begin{array}{l}\text { Utilization of proper } \\
\text { feedback tools as } \\
\text { well as assessment } \\
\text { tools }\end{array}$ & 02 \\
\hline Modifications & If Applicable & - \\
\hline
\end{tabular}

\subsection{Measuring Tools in Survey}

\subsection{Major Challenges in online teaching 3.1.1. Maintenance of social contact}

From the earlier research surveys, the one major aspect that educators encounter is better maintain of social contact with the learners and their parents. The results are pictorially depicted in Fig.1 Further, the content delivery via virtual conferencing systems served as a basic premise for online pedagogical process. As educators are concerned about enabling the learners to access a suitable part of the course curriculum content via virtually, the introduction of new portion of syllabus or content to stimulate the learner's cognitive activation raised as one of the typical challenges. The adoption of task differentiation for virtual learning enabled a means of embracing all the learners during this online teaching learning via adaptive teaching. As the learner's learning includes bridging the gap between the actual and desired performance, the educator's feedback to learners about their progress is essential [21]. Finally, educators expressed their concerns in the regard of how the assessment and evaluation could be performed when student teacher interaction is virtual and hence the online assessment became a major requirement.

In Fig.1, 1(a) represents the following statement: "I have extended my contact and helped the learners and parents who required my support during the lockdown" and 1(b) represents "I have extended my support to all the learners and parents regularly".

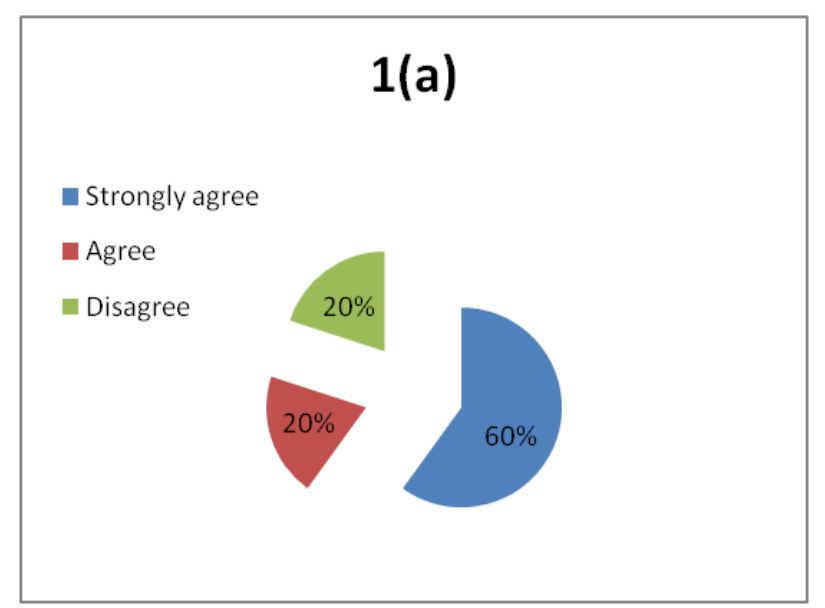

Fig.1(a)

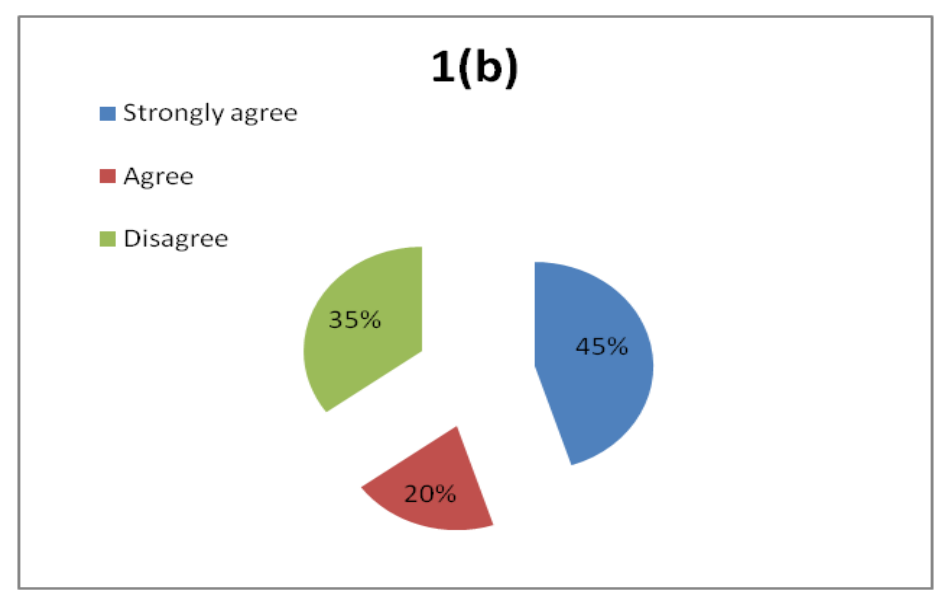

Fig.1(b)

Fig.1(a,b) Percentage of educator agreement on parameters related to maintaintenance of social contact with learners and parents

On par with the concerns and issues developed due to immediate adoption of online teaching and learning, a scale was developed to measure the social contact of educators and learners. Certain specific challenges and issues that are related to online pedagogical practice were measured by utilizing certain single variables like

a. Provision of online classes and content

b. Introduction of new learning content

c. Provision of different tasks to Student Learning Groups ( SLG's )

d. Provision of effective feedback

e. Conducting online assessments and evaluation

The results of the survey are furnished in Fig.2.The early career educators were asked to furnish these details on par with their conducted online teaching classes and experience.

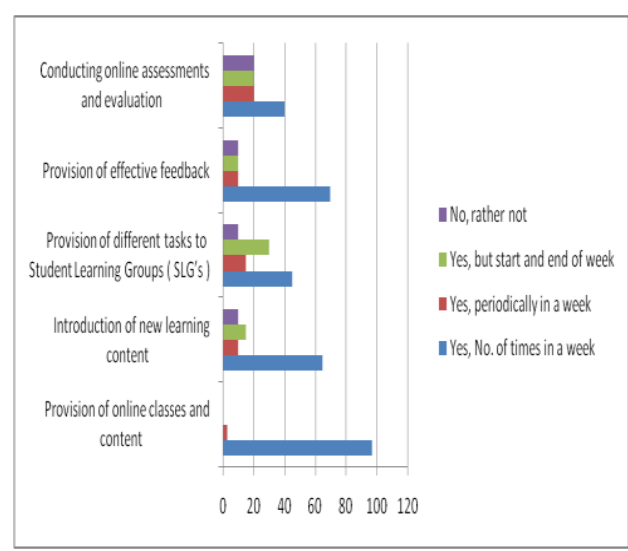

Fig. 2 Percentage of educator agreement related to specific challenges and issues related with online teaching learning process 


\subsubsection{Educator's Competence}

From the earlier research study, we analysed the educator's conceptual and situational TPK by utilizing standardized test [22]. It contains two scales in which one is related to conceptual TPK i.e., in the regard of concepts, facts and principles and the second one is related to situational TPK i.e., in the regard of practical contexts, situations and typical problems. The scales consist of total of 18 items that are provided in the earlier research. Further, we have included the revised teacher self-efficacy scale in order assess educator's self-efficacy with regards to instructions strategies i.e., how certain are you able to gauge the learners comprehension about what has been taught?, and it is rated on a scale varying from 'not at all certain' to 'absolutely certain'.

\subsection{Survey Report}

The data received from senior career educators reveal that efficacy of the online teaching should not be measured during the crisis time and further suggested that the educational curriculum in India should be restructured in order to achieve success in online teaching pedagogy as per the present situations in educational institutions except Tier 1institutions. The survey results of the early career educators represent that $80 \%$ of the people effectively communicated with the learners and parents on a regular basis as they are relatively better acquainted with ICT and hence getting better adoptive. The rest of the educators reports that due to various reasons like non-responsiveness of learners as well as parents, they were unable to maintain social contact during this period as expected though it is very important parameter to consider Further, $90 \%$ of them trying their best to enhance their teaching skills by the effective utilization of online teaching aids to make it as best as conventional pedagogical process and $10 \%$ of them reported that they are not exposed and trained for online teaching aids and hence not being utilised at all.

\subsection{Discussion}

As data reveals, all the targeted engineering educators are not in an equalized stage for better maintain of social contact with their learners and corresponding parents. It is further identified that many students are feeling social isolation and hence their response via interaction not being found satisfactory. In certain cases, the educators reported that newly introduced syllabi along with task assigning and provision of feedback to their learners is not up to the mark. Further, it is also understood that the recent adoption of online mode imposed certain challenges which clearly highlights the necessity to integrate ICT like online teaching and learning and online assessment and evaluation were mastered to a maximum extent with necessary training. On par with educator's competence, the conceptual and situational TPK are analysed by utilizing standardized test that consists of a scale ranging from 'not at all certain' to 'absolutely certain'. The educators who performed well in this test reported to have better communication with learners and parents and delivered online adaptive teaching during the closure period. In particular, adaptive teaching is considered as a decisive feature of standard and of high quality instruction. The educators' self-motivation play very important in order to provide different tasks and also providing proper feedback to the learners.

On par with our expectations, the early career educators were found at adapt and curcuma to the digitized online teaching challenges that are imposed by the pandemic as they belong to digital native generation i.e., $21^{\text {st }}$ Century learners. The forced closure of educational institutions has just made visible what the effect will be if educational institutions fail to catch-up with the basic ICT transformation process. Henceforth, it is very much required to furnish learning opportunities in professional development for educators and in training for early career as well as senior career educators. While educators may learn from reports and findings on good practice for virtual learning, the educational institutions remain the obligatory learning atmosphere for the transactions of teaching and learning process. Virtual learning of any kind cannot therefore be termed as an adequate measure to deal with the pandemic situations in a considerable manner. The educational institutions should develop certain concepts like blended learning which contains a strategic combination of learning at institute as well as at home.

\subsection{Conclusion}

The impact of COVID 19 pandemic outbreak given a huge challenges to the entire globe towards its sustainment in several aspects starting at human health. Global economy comes down to greater level in view of huge impact on the industry and other related sectors. Education sector is not an exception in this regard facing both direct and indirect impacts on the stake holders, viz., students, parents, academic fraternity. The entire educational industry is affected as sudden forced closure with a prior precautionary measure as a part of implementation of non-expansion activities of corona virus. Further, every person in the world has to learn about the utilization of communication tools virtually. Also, this study made an attempt to investigate how the engineering educators adapted to virtual or online teaching during forced closure of educational institutions. The study is aimed to answer some research questions related to how the engineering educators mastered the challenges in this pandemic situation and what are the key ways of their success in the online teaching.

Despite of findings from our present survey, limitations of this study should also be discussed. Firstly, this survey is conducted on the educators who were willing to participate in our study and the number is limited to 100 . Second, some of the measuring instruments had to be adopted timely or developed quite newer instruments, which there may be limitations. The third aspect is that the study is carried out in India; henceforth generalization of these survey results to 
other countries is hardly possible. Further, it can be concluded that this pandemic arousal has open up further relevant research in different education systems.

\section{Acknowledgements:}

The authors are very much pleased to thank all the educators who voluntarily participated in survey which really made us to clearly depict the data

\subsection{References}

1. Selwyn, N. 2012. Education in a Digital World: Global Perspectives on Technology and Education. New York, London: Routledge.

2. McFarlane, A. E. 2019. "Devices and Desires: Competing Visions of a Good Education in the Digital Age." British Journal of Educational Technology 50 (3): 1125-1136, doi:10.1111/bjet.12764.

3. Jäger-Biela, D., K. Kaspar, and J. König. 2020. "Opportunities to Learn Digital Media Competences" InEducation, School, Digitalization, 66-72. Münster: Waxmann.

4. Lipowsky, F. 2015. "Unterricht. [Teaching]." In PädagogischePsychologie [Educational

Psychology], edited by E. Wild and J. Möller, 69-105. Berlin, Heidelberg: Springer

5. Kundu, Arnab. (2018). Barriers to Utilizing ICT in Education in India with a Special Focus on Rural Areas.

6. Mehra, Lekhraj\&Mehra, Mr. (2015). Information and Communications Technology (ICT)in

Advanced Education System :Aspects and Challenges in India.

7. Huber, S. G., and C. Helm. 2020. "COVID-19 and Schooling: Evaluation, Assessment and

Accountability in Times of Crises-reacting Quickly to Explore Key Issues for Policy, Practiceand Research with the School Barometer." Educational Assessment, Evaluation and Accountability1-34. doi:10.1007/s11092-020-09322-y. 8. Eickelmann, B., and J. Gerick. 2020. "Learning withDigital Media: Objectives in Times of Corona and under Special Consideration of SocialInequities]." Die Deutsche Schule 16: 153- 162. doi:10.31244/9783830992318.09.

9. Kozma, R. B. 2011. "ICT, Education Transformation, and Economic Development: An Analysis of the US National Educational Technology Plan." E-Learning and Digital Media 8 (2): 106-120. doi:10.2304/elea.2011.8.2.106.

10. Meera. B, "Use of Information and Communication Technology in Secondary Schools", Research Report, Study commissioned by NITI AYOG, 2015.

11. Buabeng-Andoh, C. 2012. 'Factors Influencing Teachers' Adoption and Integration of Information and Communication Technology into Teaching: A Review of the Literature." International Journalof Education and Development Using ICT 8 (1): 79-105. doi:10.1080/09523987.2018.1439712.

12. Chauhan, S. 2017. "A Meta-analysis of the Impact of Technology on Learning Effectiveness of Elementary
Students." Computers \& Education 105: 14-30. doi:10.1016/j.compedu.2016.11.005.

13. Li, Q., and X. Ma. 2010. "A Meta-analysis of the Effects of Computer Technology on School Students' Mathematics Learning." Educational Psychology Review 22 (3): 215-243. doi:10.1007/s10648-010-9125-8.

14. Baker, J. P., A. K. Goodboy, N. D. Bowman, and A. A. Wright. 2018. "Does Teaching with PowerPointIncrease Students' Learning? A Meta-analysis." Computers \& Education 126: 376-387. doi:10.1016/j.compedu.2018.08.003.

15. Kaiser, G., and J. König. 2019. "Competence Measurement in (Mathematics) Teacher Education andBeyond: Implications for Policy." Higher Education Policy 32: 597-615. doi:10.1057/s41307-019-00139-z.

16. Blömeke, S. 2017. "Modelling Teachers' Professional Competence as a Multi-dimensional Construct."In Pedagogical Knowledge and the Changing Nature of the Teaching Profession, 119-135. Paris: OECD.

17. Guerriero, S., ed. 2017. Pedagogical Knowledge and the Changing Nature of the Teaching Profession. Paris: OECD. 18. Shulman, L. S. 1987. "Knowledge and Teaching. Foundations of the New Reform." Harvard Educational Review 57: 1-22. doi:10.17763/haer.57.1.j463w79r56455411.

19. Selwyn, N. 2012. Education in a Digital World: Global Perspectives on Technology and Education.New York, London: Routledge.

20. Mishra, P., and M. J. Koehler. 2006. "Technological Pedagogical Content Knowledge: A Frameworkfor Teacher Knowledge." Teachers College Record 108 (6): 1017-1054. doi:10.1111/j.1467-9620.2006.00684.x.

21. Boud, D. 2015. "Feedback: Ensuring It Leads to Enhanced Learning." The Clinical Teacher 12: 37.doi:10.1111/tct.12345.

22. Lachner, A., I. Backfisch, and K. Stürmer. 2019. "A Test-based Approach of Modeling and MeasuringTechnological Pedagogical Knowledge." Computers \& Education 142: 103645. doi:10.1016/j.compedu.2019.103645. 